\title{
Towards Innovative FRP Fabric Reinforcement in Concrete Beams: Concrete-CFRP Bond
}

\author{
Mithila Achintha ${ }^{1 *}$, Fikri Alami ${ }^{1}$, Sian Harry ${ }^{1}$, Alan Bloodworth ${ }^{2}$ \\ ${ }^{1}$ Faculty of Engineering and the Environment, University of Southampton, Southampton, SO17 1BJ \\ ${ }^{2}$ School of Engineering, University of Warwick, Coventry, CV4 7AL \\ * Corresponding Author: E-mail: Mithila.Achintha@soton.ac.uk Telephone: 02380592924
}

\begin{abstract}
The paper reports results of an experimental investigation into load response and failure behaviour of rectangular prismatic concrete beams reinforced with a combined flexural and shear reinforcement system made from carbon fibre reinforced polymer (CFRP) fabric. It is shown that CFRP U-channels with aggregate coating and an anchorage system consisting of a lipped channel section with intermittent closed loops were found to provide improved composite action between the CFRP reinforcement and concrete. These CFRP channels also ensured adequate strength and ductility before failure. Possible modes of failures of the beams are discussed as is the effect of the design parameters on the failure mode and the failure load. It is anticipated that the findings of this paper could be effectively used in other applications such as non-prismatic concrete geometries and as permanent formwork/reinforcement in thin concrete members where the flexible characteristics of dry CFRP fabrics are most useful.
\end{abstract}

\section{Keywords}

Aggregates, Beams, Bond, CFRP, Composite materials, Ductility, Failure, Fibre-reinforced polymer, Reinforcement 
2 Interest in fibre reinforced polymer (FRP) internal reinforcement in concrete is mostly focused on their use as a way to mitigate corrosion seen in conventional steel-reinforced concrete structures exposed to the environment, such as highway bridges and sea walls (Achintha, 2009). Superior mechanical properties, high tensile strength and lightweight mean FRPs are attractive in civil engineering structures. Nonmagnetic properties of FRPs also make them useful for facilities for MRI medical equipment, airport runways, electronics laboratories, etc. FRP internal reinforcements have mostly been used in the form of reinforcement bars (e.g. Manalo et al., 2014; Qin et al., 2017), whilst other reinforcement systems such as grids, fabrics, and ropes have also been sparsely used (Gudonis et al., 2013). Commercially available FRP reinforcement systems are mostly made from glass (GFRP) or carbon (CFRP) fibres embedded in a resin matrix.

'FRP-reinforced concrete' design guidelines published by national/international professional organisations (e.g. ACl 440.1R-15, 2015; CAN/CSA-S806-12, 2012, fib Bulletin No. 40, 2007) are mainly given in the form of modifications to existing limit state design principles adopted in steel-reinforced concrete codes of practice. The modifications generally take into account the intrinsic mechanical properties of FRPs, and are mostly empirical equations developed based on experimental investigations. However, the use of FRPs as a direct substitute for steel bars using the same design principles as in steel-reinforced concrete members means designs are often expensive and inefficient (Bank, 2006). There are fundamental differences between the characteristics of the two materials: FRPs are elastic and brittle whereas steel yields under high stresses. There are also major differences in the bond characteristics: with steel bars having a strong concrete-steel bond, which is advantageous since when the strain in the steel reaches the yield strain at a crack in the concrete, the steel yields and no stress concentration can occur. In contrast, failure of FRPs may be triggered by high local strains. The existing FRP internal reinforcement design guidelines are being linked to FRP bars and the guidelines are often too conservative (Bank, 2006). 
The flexible nature of FRP fabrics prior to curing with resins provides the prospect of forming novel, efficient 2D/3D reinforcement systems. Wide ranges of mechanical properties, to match the design requirements, can be obtained by combining fabric sheets in different laminate arrangements. Despite the potential of FRP fabrics to reinforce concrete, only a little research, largely external strengthening of concrete beams and columns has been reported (e.g. Punurai, 2013). Despite the high material cost of FRPs compared to traditional reinforcing materials, the economic benefits may come from less maintenance requirements and longer life. Total life cycle analyses and environmental impact assessments may be used to justify the economic viability of FRPs in the construction industry (Achintha, 2016).

This paper presents selected findings from a research programme that aimed to exploit the use of 2D multidirectional CFRP fabric as a combined flexural and shear reinforcement in concrete beams. The paper reports results of an experimental investigation of the bond behaviour of concrete beams reinforced with three different CFRP fabric reinforcement configurations; a plain U-channel, a Uchannel with an aggregate coating (i.e. a layer of aggregate applied on all surfaces of the CFRP channel using an epoxy resin and allowed to cure prior to casting concrete), and an anchorage system consisting of a lipped U-channel section with intermittent closed loops. Possible modes of failures of the beams are discussed as is the effect of the aggregate coating on FRPs and anchorages on the failure mode and the failure load. It is anticipated that the basis provided by the present work could be effectively used in applications such as combined flexural and shear reinforcement systems in structurally optimised, non-prismatic concrete members cast using flexible formwork (e.g. Orr, 2012) and as permanent formwork in novel forms of thin-shell concrete flooring system (e.g. Hawkins et al., 2017) for multi-storey buildings, where both applications have potential to create low embodied energy alternatives to respective traditional reinforced concrete applications. 
Over-reinforced designs are preferred in FRP-concrete design guidelines as a mean of mitigating potential brittle failure of FRPs. Nevertheless, the resulting compression failure of concrete is still brittle and it is not favoured in the construction industry. There is a need for innovative and costeffective FRP reinforcement systems that will ensure sufficient ductility in concrete structures whilst enabling the efficient use of high strength/strain capacities of FRPs. The existing FRP reinforcement systems are largely unidirectional. These systems are prone to brittle material/bond failures. Multidirectional FRP fabrics have potential to provide reinforcement systems which will have greater strength and ductility in more than one direction. For example, $0^{\circ}$ fibres in a multidirectional laminate can provide high strength/stiffness properties along the fibre direction, whereas $90^{\circ}$ fibres will enhance the mechanical properties in the transverse direction. On the other hand, $\pm 45^{\circ}$ fibres provide high in-plane strength and strain properties.

FRP fabrics have great potential of lending themselves to any required geometry and to provide mechanical properties to match the design requirements. Previous studies on the use of multidirectional FRP fabrics in strengthening concrete beams and columns (Punurai, 2013), FRP fabrics-fine grained concrete thin layers for retrofitting of concrete beams (Brückner et al., 2006), in thin-walled concrete facades (Shams et al., 2014), etc. demonstrated benefits such as ductile failure compared to equivalent applications of conventional FRP bars or unidirectional pre- impregnated fibre sheets. In the current study, a single combined flexural and shear reinforcement system was investigated for concrete beams. $\pm 45^{\circ}$ multi-layer CFRP fabric reinforcement systems were investigated, owing to the potential of $\pm 45^{\circ}$ fabrics to ensure greater ductility in the beams. Since the long-term performance of GRFP under some special harsh environment conditions-such as exposure to high alkalinity, seawater, or deicing salts-remains unknown (Robert and Benmokrane, 2013), CFRP fabrics were chosen in the current study. 


\section{Concrete-FRP bond}

80

81

82

Concrete-FRP bond is the single most important parameter that governs load response and failure behaviour of FRP reinforced concrete beams. The characteristics of the concrete-FRP bond have been extensively studied in the literature, mostly using the experiments of pull-out tests of FRP bars in concrete (e.g. Achillides and Pilakoutas, 2004; Aiello et al., 2007). Limited research on bending tests that represents FRP as flexural reinforcement in concrete beams has also been reported (e.g. Ashtiani et al., 2013). The poorer bond performance of the concrete-FRP bars when compared to steel reinforcement is well known (Larralde and Silva-Rodriguez, 1993). Different types of surface deformation systems of the FRP, in particular, sand-coated FRP bars are known for their promise in enhancing bond strength whilst eliminating premature debonding failure (Baena et al., 2009).

The technique of sand-coatings on FRPs has not been widely explored for 2D/3D internal FRP reinforcement systems such as CFRP channels. The limited applications of sand/aggregate coatings has primarily been on tensile/shear pull-out experiments of FRP laminate coupons; experimental investigations suggested improved bond strength and less brittle failure behaviour (e.g. Wang et al., 2014; Cho et al., 2010; Li et al., 2014). The improvements in the composite action between FRP and concrete may be attributed to mechanical interlocking and the improved bond between aggregate coating and the cement paste (Wang et al., 2014; Li et al., 2014). The feasibility of epoxy-bonded aggregate coatings to improve composite action between concrete and FRP has also been demonstrated in applications of pultruded FRP planks as permanent formwork in concrete-FRP hybrid bridge decks (Bank et al., 2007).

The average bond strength determined from tensile and shear pull-off tests of aggregate-coated FRP coupons reported in Wang et al. (2014) depended on the size of the aggregate in the coating layer; for example, aggregate of size 3.15-4.75 $\mathrm{mm}$ resulted in higher average bond strength compared to that noted for aggregate of size 1.25-2.36 mm. Experimental results (Wang et al., 2014) also suggested the 
effect of aggregate size on failure mode: failure in concrete was noted when aggregate of size 1.18-

$4.75 \mathrm{~mm}$ was used in the coating, whereas epoxy failure was noted when large aggregate of size 6.70-

$9.52 \mathrm{~mm}$ was used. Mixed-mode failure was noted when aggregate coatings had particles of size 4.00-

$7.00 \mathrm{~mm}$ (Cho et al., 2010). The possible influence of the distribution density of aggregate in the coating on concrete-FRP bond was also noted (Cho et al., 2010), nevertheless, the reported results are insufficient to establish verified conclusions.

\section{Anchorage mechanisms for preventing premature debonding of the concrete-FRP bond}

Premature failure of concrete-FRP bond is common in all concrete-FRP hybrid systems; debonding usually triggers at high stress concentration features or at locations where interface cracks/flaws are present. Despite the significant improvements in bond properties of aggregate-coated FRP-concrete bond, debonding was not completely eliminated (e.g. Bank et al., 2007; Li et al., 2014). Debonding was also noted with sand-coated FRP bars (Cosenza et al., 1997) as well as in externally bonded FRP systems on concrete beams for flexural/shear strengthening/retrofitting purposes (Achintha and Burgoyne, 2012). Extensive research on debonding of externally bonded FRPs from concrete has identified that provision of anchorages in the vicinities where the FRP curtails has potential to eliminate debonding and to improve the overall structural performance (Grelle and Sneed, 2013).

\section{Experimental programme}

124 In the first half of the experimental programme, three concrete beams, each with dimensions 1000 $\mathrm{mm}$ (length) x $120 \mathrm{~mm}$ (width) $\times 120 \mathrm{~mm}$ (depth), reinforced with three different forms of CFRP fabric reinforcement: a plain U-channel (B1), a U-channel with aggregate coating (B2), and an anchorage system consisting of a lipped U-channel with intermittent closed loops (B3) (Fig. 1a), were tested. Aggregate coating was used as a means of improving the composite action between concrete and the CFRP reinforcement, whereas a lipped channel section with intermittent closed loops was chosen to 
into account the results of these three beams, a beam reinforced with a lipped CFRP U-channel with intermittent closed loops and an aggregate coating on all internal and external surfaces (B4) was designed and tested in the second half of the experimental programme as a mean to achieve stronger and stiffer beams with improved post-breakage strength and ductility. For comparison of the results, a reference beam (B5) of the same dimensions as B4, but with a plain CFRP U-channel was also fabricated and tested. The objective of this experimental programme was not to provide design data but to demonstrate the basic mechanics of concrete beams reinforced with CFRP fabric reinforcement. Although a combined flexural/shear reinforcement system was provided, the experiments aimed to investigate the flexural behaviour of the beams. A detailed shear analysis of the beams was beyond the scope the study, however, an approximate shear design was used to ensure no premature shear failure prior to the expected flexural failure. The design of the CFRP fabric reinforcement systems was not trivial; the analyses adopted in the currents study will be presented in a future publication.

\section{Materials}

All three test beams were made using the same materials, fabrication techniques, and curing conditions. The CFRP channels were first fabricated and then concrete was cast once the CFRP channels had fully cured.

$\pm 45^{\circ}$ biaxial carbon fibre dry fabric (Fig. 1b) (weight $300 \mathrm{~g} / \mathrm{m}^{2}$ and thickness $0.35 \mathrm{~mm}$ ), purchased from a commercial supplier was used to fabricate the reinforcement channels. Four plies of dry CFRP fabrics were first individually impregnated with an epoxy laminating resin in combination with a slow hardener using a wet lay-up fabrication technique and then layered each one on top of the other in order to fabricate a four-layer laminate. A slow hardener was chosen because of longer workability time and the flexibility it provided for fabricating U-channels. With a dry fabric thickness of $\sim 0.35 \mathrm{~mm}$ and a total resin thickness of $\sim 0.25 \mathrm{~mm}$, the thickness of the laminate was $\sim 1.65 \mathrm{~mm}$. The laminate was symmetric, since for each layer on one side of the mid-plane there was a corresponding layer at 
equal distance from the mid-plane on the other side with identical elastic mechanical properties and layer thickness; this ensures no coupling between in-plane loading and bending deformations. Similarly, the laminate was balanced since it had pairs of layers with identical elastic mechanical properties and thicknesses, but with $+45^{\circ}$ and $-45^{\circ}$ fibre orientations with respect to the longitudinal axis; this eliminates coupling between normal loading and in-plane shear deformations.

162

The concrete mix was designed in accordance with ‘BRE Design Manual' (BRE, 1997). A high slump (60$180 \mathrm{~mm}$ ) and small aggregate (10 $\mathrm{mm}$ maximum size) were chosen to ensure the workability required to cast the beams of small dimensions. Fine aggregate with $100 \%$ passing through $600 \mu \mathrm{m}$ sieve was used. Concrete was cast in situ in accordance with the requirements specified in BS EN 206 (2013). The average 28-day compressive strength of the concrete was determined to be $\sim 38 \mathrm{MPa}$.

\section{CFRP fabric reinforcement systems}

Plain U-channel

The plain U-channel was fabricated from $970 \mathrm{~mm} \times 230 \mathrm{~mm}$ CFRP fabric sheets in order to achieve the dimensions $970 \mathrm{~mm} \times 80 \mathrm{~mm} \times 80 \mathrm{~mm}$ of the channel (Fig. 2a). The required U-shape was obtained by wrapping the wet, rectangular laminate around a foam mould (Fig. 2b). The CFRP-wrapped foam mould was then positioned within a plywood formwork (Fig. 2c) and cured in ambient conditions $\left(20 \pm 2{ }^{\circ} \mathrm{C}\right)$ for two days. Thin release films that leaves no residues were used between the CFRP and the foam and also between the CFRP and the plywood. In order to limit the effects of stress concentrations, the corners of the channel were rounded. Although autoclave or resin infusion techniques have potential to produce higher quality products than the wet lay-up method used here, advanced manufacturing methods were beyond the scope of the study, since the objective was to demonstrate the use of novel forms of fabric reinforcement in concrete beams. 


\section{U-channel with aggregate coating}

The aggregate-coated CFRP channel adopted the same section dimensions, manufacturing and curing methods as the plain U-channel. However, once the CFRP had cured, an aggregate coating was applied on all internal and external faces (Fig. 1a). The size of the aggregate particles and surface density were chosen to achieve desirable benefits.

\section{Size and spatial distribution of aggregate coating}

Aggregate of size 2-5 $\mathrm{mm}$ was chosen considering the improved bond properties and the favourable concrete substrate failure reported in the literature for coating with particles of this size range. Dried quartz gravel purchased from a commercial supplier was used. Fig. 3a shows the distribution of the particle size, obtained from a sieve analysis conducted in accordance with BS 1377: Part 2 (1990) using an automatic sieve shaker (vibration amplitude $5.5 \mathrm{~mm}$ and over a 10-minutes duration) with sieve sizes $1.18 \mathrm{~mm}, 2.00 \mathrm{~mm}, 3.35 \mathrm{~mm}, 5.00 \mathrm{~mm}$ and $6.30 \mathrm{~mm}$. As can be seen from Fig. 3a, the particles were within the required size range $(2-5 \mathrm{~mm}$ ). Particles less than $1.18 \mathrm{~mm}$ in size (only $0.16 \%$ by weight of total particles) were removed, since such small particles were not previously used in aggregate coatings. $\sim 50 \%$ surface distribution density of aggregate coating was chosen as a reasonable starting point in the investigation, in order to achieve improved bond properties whilst providing adequate space for mechanical interlock between the coating and in situ concrete. The volume of aggregate required for $\sim 50 \%$ coverage of the total surface area of the CFRP channel was determined by using the knowledge of the volume of aggregate required for an approximate $100 \%$ surface coverage of a known surface area of the CFRP. In the present study, one sixth of the required total volume of aggregate was applied on all surfaces of each one sixth length of the CFRP channel.

\section{Application of aggregate coating}

The same epoxy resin and the mix ratio used in the CFRP channels was also used to bond the aggregate on the surfaces of the CFRP channel. The thickness of the resin layer was maintained to be $\sim 0.5 \mathrm{~mm}$ 
in order to achieve a sufficient submersion of the aggregates whilst eliminating complete coverage of aggregate (a 'smoothing' effect caused by the full coverage of epoxy on aggregate can weaken the CFRP-concrete bond (Bank et al., 2007)). The aggregate coating was applied on two horizontal surfaces at a time (see Fig. 3b), and once the resin adhesive had fully cured (usually after 24 hours), coating was applied on another two surfaces of the CFRP channel (see Fig. 3b). Generally, an even layer of aggregate was applied on all surfaces, although due to the curvature at the corners of the channel small slippages and movement of the aggregate were unavoidable.

\section{Lipped U-channel with intermittent closed loops} In order to investigate the effect of anchorage at high stress locations of the concrete-CFRP bond, a lipped U-channel with intermittent closed loops was investigated (Fig. 1a). Conversely to the other two channels, this CFRP channel was made using two dry fabric plies of size $970 \mathrm{~mm} \times 230 \mathrm{~mm}$ and two larger plies of size $970 \mathrm{~mm} \times 332 \mathrm{~mm}$. The larger plies were cut on each side to create a series of anchorage tabs (each of width $60 \mathrm{~mm}$ and length $74 \mathrm{~mm}$ ), as shown in Fig. 4a. When stacking the plies during the wet lay-up process, tabbed plies were positioned in the middle, with others located on the top and bottom as shown in Fig. 4a. Tabs on one side of the laminate were first wrapped over the foam mould, and then those on the other side were wrapped over the first to make the required intermittent closed loops (Fig. 4b). Intermittent gaps of $120 \mathrm{~mm} \times 40 \mathrm{~mm}$ in plan were left between the closed loops in order to facilitate concrete casting. The CFRP channel was cured in the same way as the other two channels.

\section{Concrete beam casting and test set up}

Two linear strain gauges (gauge length $\sim 6 \mathrm{~mm}$ and grid resistance $120 \pm 0.3 \Omega$ ) were fixed along the two fibre direction at midspan of each CFRP channel on the bottom surface. Although strain gauge rosettes would have been an alternative, the relatively large rosette could weaken the surrounding concreteFRP bond, therefore, strain gauges which are much smaller than a rosette were used. In order to 
improve the bond between plain CFRP channels and in situ concrete (i.e. in B1 and B3), a thin wet epoxy resin layer was applied $\sim 45$ minutes prior to concrete casting on all surfaces of the CFRP channels. No epoxy resin was applied to the aggregate-coated channel (B2) in order to eliminate potential 'smoothing' of the aggregate surfaces. The three concrete beams were cast and cured in ambient conditions.

Beams were tested after 28 days of curing in four-point bending (Fig. $5 \mathrm{a}$ ) (shear span $=325 \mathrm{~mm}$, constant moment zone $=250 \mathrm{~mm}$ ) using a servo-hydraulic test machine, displacement controlled (stroke rate of $2 \mathrm{~mm} / \mathrm{min}$ ). Midspan deflection was measured using two digital displacement gauges, located at the front and back of the beam.

\section{Experimental results}

\section{Load-midspan deflection relationship}

Fig. $5 \mathrm{~b}$ shows load-midspan deflection relationships of the three beams. As expected, the behaviour of the three beams were similar within the uncracked regime of concrete. The results suggest that in all beams flexural cracks first developed at applied load $\sim 7.5 \mathrm{kN}$, where the corresponding midspan deflection was $\sim 0.6 \mathrm{~mm}$. As expected, after the formation of flexural cracks, beams showed reduction in flexural stiffness. As can be seen from the figure, B2 demonstrated a higher bending stiffness and failure load compared to B1 and B3. This suggests the improved bond and composite action between concrete and CFRP in B2. The peak load of $\sim 46.65 \mathrm{kN}$ of B2 is significantly higher than those of 29.88 $\mathrm{kN}$ and $30.86 \mathrm{kN}$ of $\mathrm{B} 1$ and $\mathrm{B} 3$ respectively.

\section{Ductility}

Since the tests were conducted displacement controlled, the post-peak behaviour of the beams was also observed (Fig. 5b). All beams resisted applied load beyond the peak load demonstrating notable ductility before final failure. The beams failed at loads $25.90 \mathrm{kN}, 23.74 \mathrm{kN}$ and $23.38 \mathrm{KN}$ respectively; 

respective failure loads were $17.2 \mathrm{~mm}, 15.9 \mathrm{~mm}$ and $20.2 \mathrm{~mm}$, whereas deflections at the respective peak loads were $8.5 \mathrm{~mm}, 9.7 \mathrm{~mm}$ and $12.2 \mathrm{~mm}$. 'Ductility index' may be defined as the ratio of the additional midspan deflection after the peak load to the midspan deflection at the peak load; ductility indices of the three beams are $102.4 \%, 63.9 \%$ and $91.6 \%$ respectively. The results suggest that, unlike conventional applications of FRP bars and other FRP internal reinforcements in concrete beams where brittle failures were inevitable, beams B1, B2 and B3 demonstrated significant ductility and safe failure behaviour. A further advantage of the beams may be explored: the beams recovered the deflection upon unloading, as shown in Fig. 5b. The residual midspan deflections of the three beams were 7.9 $\mathrm{mm}, 2.6 \mathrm{~mm}$ and $8.9 \mathrm{~mm}$ respectively (the corresponding recovery of the midspan deflection from the failure load were $54.1 \%, 83.6 \%, 55.9 \%)$. This suggests that a large part of the energy put into the beam during loading has dissipated rather than storing as strain energy; this ensures no explosive failure.

\section{Analysis of failure}

Fig. 6a shows the applied load-strain relationships at midspan of all three test beams. Strains at the top surface of the beam (i.e. compression surface) and the strain in the CFRP along the fibre direction are shown in the figure. As noted previously, CFRP strain was measured along both fibre directions average of the two measured strains is shown in Fig. 6 a.

\section{Strain in CFRP}

As expected, the CFRP experienced higher strains after the development of flexural cracks in the beams. It should be noted that, due to the failure of strain gauges, the CFRP strain in B3 was recorded only up to applied load $14.95 \mathrm{kN}$. Fig. 6a shows that the CFRP strains at the peak loads of B1 and B2 
study of the authors (Achintha et al., 2015), it was noted that tensile and shear failure strains of the same CFRP laminate were greater than $\sim 0.016$. Thus, the results suggest that the CFRP did not rupture in the beams.

\section{Strain in concrete}

As can be noted from Fig. 6a, the compressive strains at the peak load of the three beams were $0.001869,0.002617$ and 0.002990 respectively. The observation of the failure mode of the beams (Fig. 6b) suggests the concrete compression zone failed in all beams. However, the noted strains in concrete (Fig. 6a) at the peak loads are significantly lower than the expected ultimate compressive strain of concrete ( 0.0035) (Eurocode 2, 2004). Test results of a steel-reinforced beam made from the same concrete and tested as a control beam in the current study confirmed a concrete failure strain of $\sim 0.0033$ (see Fig. 6a). The results suggest that the failure of B1, B2 and B3 was not conventional concrete compression failure, as described presently.

\section{Crack patterns}

All beams showed similar even distribution of flexural cracks within the constant moment zone and a nominal number of minor cracks within shear spans. All beams exhibited horizontal 'splitting' cracks on the top and side surfaces (Fig. 7). Visual observations during testing confirmed that 'splitting' cracks on the top surface occurred prior to the development of horizontal 'splitting' on the sides of beams. The 'splitting' cracks on the top surface were first observed after the peak load; for example, top surface 'splitting' cracks on B2 and B3 were first observed at load $\sim 42 \mathrm{KN}$ and $\sim 28.2 \mathrm{kN}$ respectively during the post-peak regime (note: observations were not made during the testing of B1). Analysis of crack patterns suggests that all beams underwent similar failure mechanisms.

\section{Failure mechanism}

Under bending, the top surface region of the constant moment zone of the beams has subjected to high axial compression forces. In concrete, forces are mainly transferred from aggregate to aggregate, 
which are randomly distributed. Under uniaxial compression, tensile forces develop in the lateral direction in order to balance the lateral component of the compressive force between adjacent aggregate those are essentially not aligned along a direction parallel to the longitudinal axis of the beam. Coalescence of microcracks and unstable growth of microcracks around the aggregate usually starts at applied stress of $\sim 90 \%$ of the peak compressive stress (strain $\sim 0.0014$ ) (Hus et al., 1963). In the beams, the top of the CFRP channel was located $20 \mathrm{~mm}$ below the top surface of the beam. A weak bond between concrete and CFRP and flaws/voids larger than those normally expect in pure concrete are expected in the vicinity where the vertical sides of the CFRP channels were terminated. Thus, as noted in the experiments (Fig. 7), development of major cracks in the compression zone, just above the CFRP curtailment location, parallel to the beam length (i.e. perpendicular to the lateral tensile stress) is expected under continued increase in the applied load. As can be seen in Fig. 7, the major crack locations on the top surface in B1 and B2 were offset by $20 \mathrm{~mm}$ from the beam edge and channel.

It should be noted the concrete cover spalling off once flexural cracking occurs did not happen in the beams tested in the study. This behaviour may be attributed to the bond improvement mechanisms used in the beams (i.e. applications of 1. an epoxy layer (Beams B1, B3 and B5) and 2. an aggregate coating (Beam B2 and B4), on all surfaces (including the outer surfaces) of the CFRP channel); and the failure happened in the compression zone of the beam. A detailed study of the potential danger of cover spalling off once flexural cracking occurs and the effects of freezing and thawing on spalling is beyond the scope of the present paper.

\section{Narrow concrete compression zone}

Fig. 8a shows the neutral axis depth (pre-peak load regime only) measured from the top surface of the beam, calculated based on an assumed linear strain distribution at midspan through the beam section 
and using the strain values measured on the concrete at the top surface and on the side of the beam $20 \mathrm{~mm}$ below the top surface. Although the use of closely spaced strain readings (on top and $20 \mathrm{~mm}$ below that) where the top strain gauge was at the beam centreline whilst the other was on the side surface with $60 \mathrm{~mm}$ offset from the centreline to infer the through-depth strain profile may only provide an approximate estimate of the neutral axis depth, the authors believe the neutral axis data shown in Fig. 8a may still be reasonably accurate for comparisons purposes. For brevity, only neutral axis depth at relatively high applied loads (above $7 \mathrm{kN}$ ) is shown in the figure. As expected, the neutral axis depth decreased with the applied load. The applied load-neutral axis depth relationships for B1 and B3 are similar, suggesting similar load sharing behaviour of the two beams, whereas the different level of composite action between the CFRP reinforcement and concrete in B2 is evident from its notably different neutral axis location compared to B1 and B3. The neutral axis depths of the three beams at the respective peak loads are approximately $17 \mathrm{~mm}, 27 \mathrm{~mm}$ and $15 \mathrm{~mm}$ respectively. The estimated neutral axis depth is used below for explaining the crack pattern and the final failure location observed in the test beams.

\section{Final failure mode}

Observation of crack patterns and the analysis of strain data suggest that a major 'split' was developed in the beam midspan just above the side of CFRP channel. Consequently, a narrow zone of concrete ( $20 \mathrm{~mm}$ wide in B1 and B2 and $\sim 40 \mathrm{~mm}$ wide in B3), between the crack and the side of beam, was formed. Given the shallow depth of the compression zone $(\sim 17 \mathrm{~mm}, \sim 27 \mathrm{~mm}$, and $\sim 15 \mathrm{~mm}$ in B1, B2 and B3 respectively), under the high axial compression, the laterally unsupported narrow zone of concrete became the equivalent of a slender 'column', as shown in Fig. 8b. Given the no upward resistance to buckling, the 'slender concrete column' bent/buckled outwards, causing failure at the middle region of the 'concrete column'. The agreement between the crack locations on the side of the beams (Fig. 7) with the neutral axis depth at the peak load (Fig. 8a), justifies the failure mechanism 
identified above. Once the 'edge columns' had failed, the area of the concrete compression zone was reduced, and subsequently caused the complete failure of the beam.

\section{Overall performance}

The results confirmed that the use of an aggregate coating on the surfaces of the CFRP reinforcement enhanced the composite action between CFRP and concrete, subsequently ensured a higher strength and stiffness in the beam. However, the drop in the load resistance after the peak load was quite high ( $50 \%$ of the peak load) and the ductility index is modest (63.9\%). In contrast, the lipped CFRP channel section with intermittent closed loops (B3) ensured a greater ductility (91.6\%) and ability to resist a significant part of the peak load ( $>75.8 \%$ of the peak load) during the post-peak regime.

\section{New beam design}

After taking into account the results of the previous three beams, a beam reinforced with a lipped

CFRP U-channel with intermittent closed loops and an aggregate coating on all internal and external surfaces was designed and tested (Beam B4) as means to achieve stronger and stiffer beams with improved post-breakage strength and ductility. In order to demonstrate the applicability of the earlier research findings to beams with different design parameters, the dimensions and the concrete strength (25 MPa) of the new beam (B4) were chosen to be different to those of the previous three beams. The cross section of the aggregate-coated CFRP channel used in B4 was $100 \mathrm{~mm} \times 70 \mathrm{~mm}$ and it had lips of $20 \mathrm{~mm}$ wide and intermittent closed loops (Fig. 9a). The size of the lips and the spacing of the tabs were chosen to provide sufficient space for the application of aggregate coating and concrete casting. Fabrication of the CFRP channel and aggregate coating were done in the same way as for B2 and B3. The overall dimension of the concrete beam was $1370 \mathrm{~mm} \times 150 \mathrm{~mm} \times 100 \mathrm{~mm}$. For comparison of the results, a reference beam (B5) of the same dimensions as B4, but with a plain CFRP U-channel was also fabricated and tested. Beams B4 and B5 were tested in four-point bending similar to the previous three beams, but with shear span $510 \mathrm{~mm}$ and constant moment zone of $250 \mathrm{~mm}$ (the 
clear span of the beam was $1270 \mathrm{~mm}$ ). Strain gauges were fixed on the CFRP channel and concrete at beam midspan.

392

Similar to the previous three beams, B4 and B5 demonstrated even distributions of flexural cracks

within the constant moment zone and nominal numbers of minor cracks within the shear spans. Both

beams failed in the same way as the three previous beams where separation of a narrow concrete slit above the top edge of the CFRP channel at midspan was followed by buckling/bending of a narrow concrete column (Fig. 8b). Fig. 9b shows the load-midspan deflection relationships. As expected, beam B4 showed a higher strength (peak load $14.1 \mathrm{kN}$, which is equivalent to the design load if the beam had been reinforced with two $10 \mathrm{~mm}$ diameter steel bars of yield strength $500 \mathrm{MPa}$ ), flexural stiffness, and ductility (ductility index 58.8\%) compared to B5 (peak load $10.9 \mathrm{kN}$ and ductility index 24.4\%). Similar to B2, B4 demonstrated greater strength and stiffness due to improved composite action between the CFRP channel and concrete. However, the drop in load after the peak load in B4 was $23.8 \%$, compared to $49.1 \%$ in B2; this suggests the contribution of the anchorages for an improved post-breakage behaviour.

405

Fig. 10 shows the top surface strain and CFRP strain against applied load at beam midspan. The results suggest that the compressive strain at the top surface of B5 at the peak load is 0.00188 and this value matches with that in B1 (0.001870) which had a similar reinforcement arrangement. The compressive strain at the top surface of B4 at the peak load is 0.00286 ; this value is significantly higher than that noted in B5, but, as expected, it is between the corresponding values of 0.002617 and 0.002990 noted in B2 and B3 respectively. The midspan CFRP strains shown in Fig. 10 also highlight the improved 412 strength and ductility characteristics of B4 compared to B5. The CFRP strains at the respective peak 413 loads of B4 and B5 are 0.0113 and 0.00628 , and those at the respective failure loads are 0.0202 and 414 0.098. These results suggests better utility of the CFRP reinforcement in B4 compared to B5. It should be noted that the reason for the apparently high CFRP strains in B4 and B5 compared to the three 
previous beams is because in B4 and B5 the CFRP strains were recorded along the longitudinal direction of the beam (i.e. $45^{\circ}$ angle to the fibre directions), whereas in B1, B2 and B3 the strains were measured along the two fibre directions. An analysis of $2 \mathrm{D}$ strain behaviour of the CFRP channels is beyond the scope of current paper, and such analysis will be carried out by the authors in a future publication.

\section{Conclusions}

- The study has shown that concrete-CFRP bond influences the strength and ductility of concrete beams reinforced with CFRP fabric reinforcement.

- It has been experimentally shown that use of an aggregate coating on the surfaces of CFRP improved the composite action between the CFRP channel and concrete, thereby improving strength and stiffness of the beam compared to plain CFRP channel reinforcement. On the other hand, the provision of anchorage mechanisms at the top edges of the CFRP reinforcement ensured a better post-breakage resistance and ductility compared to plain U-channels.

- A U-channel with aggregate coating and an anchorage system consisting of a lipped channel section

431 with intermittent closed loops was found to provide an improved composite action between the 432 CFRP and concrete and also provided satisfactory ductility before final failure.

- It was found that the final failure mode was concrete failure in the compression zone, induced by a

434 horizontal splitting developed just above the top edge of the CFRP channel causing a narrow slither 435 of concrete to bend/buckle outwards. However, since a small number of test specimens of 436 dimensions smaller than real-life beams were tested in the present study, a more generic validation 437 of the results may be required. Challenges such as fabrication and connecting CFRP channels in long, real-life beams should also be addressed in detail.

- It is anticipated that the basis provided by the present work could be effectively used in other applications such as non-prismatic geometries and permanent formwork/reinforcement in thin 

preparation of CFRP reinforcement may be most useful.

\section{Data access statement}

Supplementary data associated with this article is openly available from the University of

Southampton repository at https://doi.org/10.5258/SOTON/D140.

\section{Acknowledgements}

Funding from the Institution of Civil Engineers (ICE) Research and Development Enabling Trust Award 2014 and the PhD sponsorship received by the second author from Directorate General of Higher Education, Indonesia (DIKTI) are greatly acknowledged.

452

\section{References}

ACl (American Concrete Institute) (2015) ACl 440.1R-15: Guide for the Design and Construction of Structural Concrete Reinforced with Fiber-Reinforced Polymer Bars. American Concrete Institute, Farmington Hills, MI, USA.

Achillides Z and Pilakoutas K (2004) Bond behavior of fiber reinforced polymer bars under direct pullout conditions. Journal of Composites for Construction 8(2):173-181.

Achintha M (2016) Environmental impact and embodied energy. Composites UK, Hemel Hempstead, UK. See https://compositesuk.co.uk/compositematerials/applications/construction/technical-sheets (accessed 12/12/2016)

Achintha M (2009) Fracture analysis of debonding mechanism for FRP plates. PhD Thesis, University of Cambridge, UK.

Achintha M, Alami F and Bloodworth A (2015) An CFRP Fabrics as Internal Reinforcement in Concrete Beams. In Proceedings of the 7th Conference on Advanced Composites in Construction (Lees J (ed)). NetComposites Ltd, Chesterfield, UK, pp. 34-40.

Achintha M and Burgoyne C (2012) Prediction of FRP debonding using the global-energy-balance approach. Magazine of Concrete Research 64(11): 1033-1044.

Aiello MA, Leone M and Pecce M (2007) Bond performances of FRP rebars-reinforced concrete. Journal of Materials in Civil Engineering 19(3): 205-213. 
Ashtiani MS, Dhakal RP, Scott AN and Bull DK (2013) Cyclic beam bending test for assessment of bond-slip behavior. Engineering Structures 56: 1684-1697.

Baena M, Torres L, Turon A and Barris C (2009) Experimental Study of Bond Behaviour Between Concrete and FRP Bars Using Pull-out Tests. Composites Part B: Engineering 40(8): 784-797.

Bank LC (2006) Composites for Construction: Structural Design with FRP Materials. John Wiley \& Sons, New Jersey, USA.

Bank LC, Oliva MG, Bae HU, Barker JW and Yoo SW (2007) Pultruded FRP Plank as Formwork and Reinforcement for Concrete Members. Advances in Structural Engineering 10(5): 525-535.

BRE (Building Research Establishment) (1997). Design of normal concrete mixes, 2nd edition. Building Research Establishment, Watford, UK.

Brückner A, Ortlepp R and Curbach M (2006) Textile reinforced concrete for strengthening in bending and shear. Materials and Structures 39(8): 741-748.

BSI (British Standards Institution) (2013) BS 206:2013: Concrete - Specification, performance, production and conformity. BSI, London, UK.

BSI (British Standards Institution) (1990) BS 1377-2:1990: Methods of Test for Soils for Civil Engineering Purposes. BSI, London, UK.

Canadian Standards Association (2012) CAN/CSA-S806-12: Design and Construction of Building Structures with Fibre-reinforced Polymers. Canadian Standards Association (CSA) International, Toronto, Canada.

CEN (European Committee for Standardisation) (2004) Eurocode 2: Design of Concrete Structures. European Committee for Standardisation (CEN), Brussels, Belgium.

Cho J, Cho K, Park SY, Kim ST and Kim B (2010) Bond Characteristics of Coarse Sand Coated Interface Between Stay-in-place Fibre-reinforced Polymer Formwork and Concrete Based on Shear and Tension Tests. Canadian Journal of Civil Engineering 37(5): 706-718.

Cosenza E, Manfredi G and Realfonzo R (1997). Behavior and modeling of bond of FRP rebars to concrete. Journal of Composites for Construction 1(2): 40-51.

fib (The International Federation for Structural Concrete) Bulletin No. 40 (2007) FRP reinforcement in RC structures. The International Federation for Structural Concrete, Lausanne, Switzerland.

Grelle SV and Sneed LH (2013) Review of Anchorage Systems for Externally Bonded FRP Laminates. International Journal of Concrete Structures and Materials 7(1): 17-33.

Gudonis E, Timinskas E, Gribniak V, Kaklauskas G, Arnautov AK and Tamulenas V (2013) FRP reinforcement for concrete structures: state-of-the-art review of application and design. Engineering Structures and Technologies 5(4): 147-158. 
Hawking W, Orr J, Ibell J, Shepherd P (2017) Developing an innovative lightweight concrete

505

506

507

508

509

510

511

512 flooring system for sustainable buildings. IABSE Conference-Creativity and Collaboration 108: 45-46, April 19-20, Bath, United Kingdom.

Hsu TTC, Slate FO, Sturman GM and Winter G (1963) Microcracking of plain concrete and shape of the stress-strain curve. ACl Journal 60(14): 209-224.

Larralde J. and Silva-Rodriguez R (1993) Bond and Slip of FRP Rebars in Concrete. Journal of Materials in Civil Engineering 5(1): 30-40.

Li M, Liu Y, Liu M and Wang F (2014) Research on a novel technology of FRP bonded to concrete substrate without adhesive. In Proceedings of Construction Materials and Structures (Ekoluet et al. (eds)). IOS Press, Amsterdam, The Netherlands, pp. 347-353.

Manalo A, Benmokrane, Park K and Lutze D (2014) Recent developments on FRP bars as internal reinforcement in concrete structures. Concrete in Australia 40(2): 46-56.

Orr JJ (2012) Flexible formwork for concrete structures. PhD Thesis, University of Bath.

Punurai W, Hsu CT, Punurai S and Chen J (2013) Biaxially loaded RC slender columns strengthened by CFRP composite fabrics. Engineering Structures 46: 311-321.

Qin R, Zhou A and Lau D (2017) Effect of reinforcement ratio on the flexural performance of hybrid FRP reinforced concrete beams. Composites Part B: Engineering 108: 200-209.

Robert M and Benmokrane B (2013) Combined effects of saline solution and moist concrete on long-term durability of GFRP reinforcing bars. Construction and Building Materials 38: 274-284.

Shams A, Horstmannb M and Heggera J (2014) Experimental investigations on Textile-Reinforced Concrete (TRC) sandwich sections. Composite Structures 118: 643-653.

Wang F, Li M and Hu, S. (2014) Bond behavior of roughing FRP sheet bonded to concrete substrate. Construction and Building Materials 73: 145-152.

8

.

(1)

1

2

3

4

6


(a)

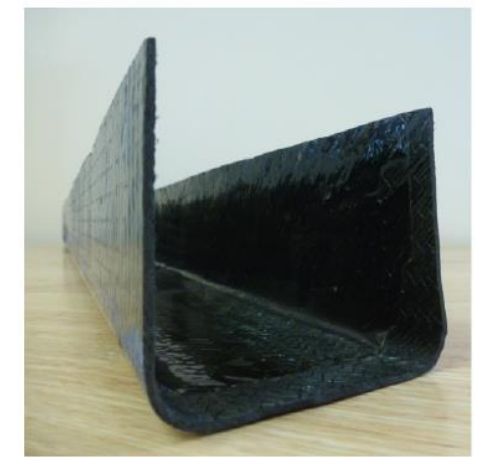

Plain U-channel

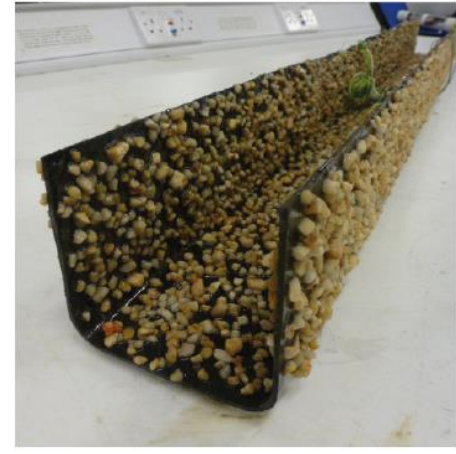

U-channel with aggregate coating

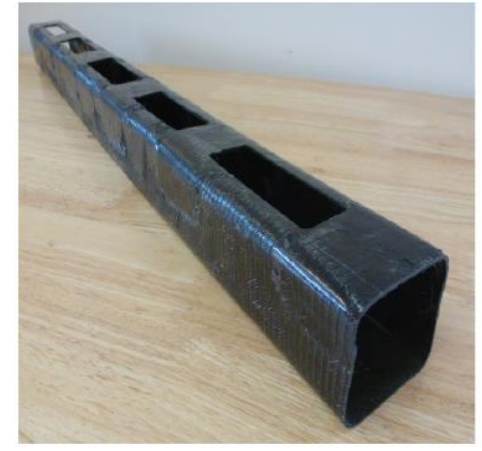

Lipped cannel channel with interminent closed loops

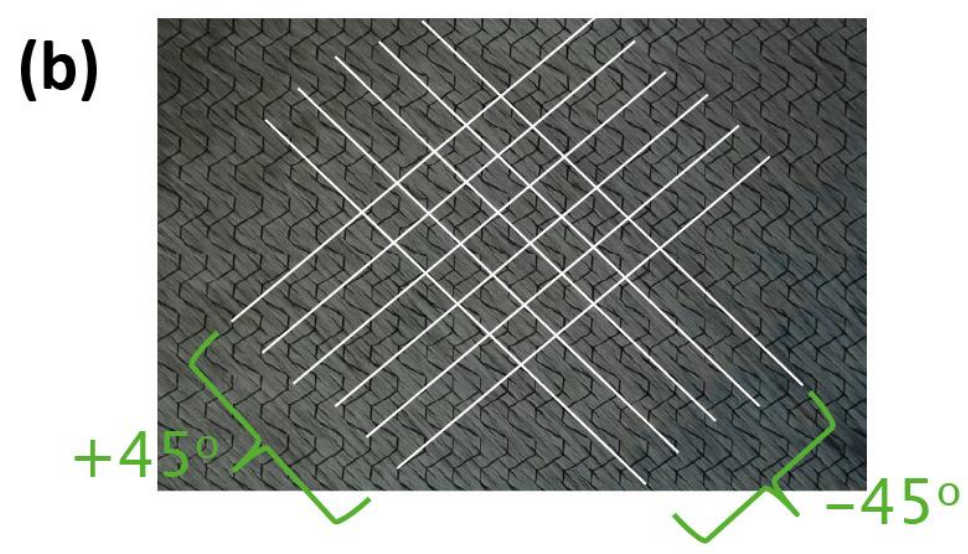

Fig. 1. (a) Three types of CFRP fabric channel reinforcement $\quad$ (b) $\pm 45^{\circ}$ biaxial CFRP dry fabric 


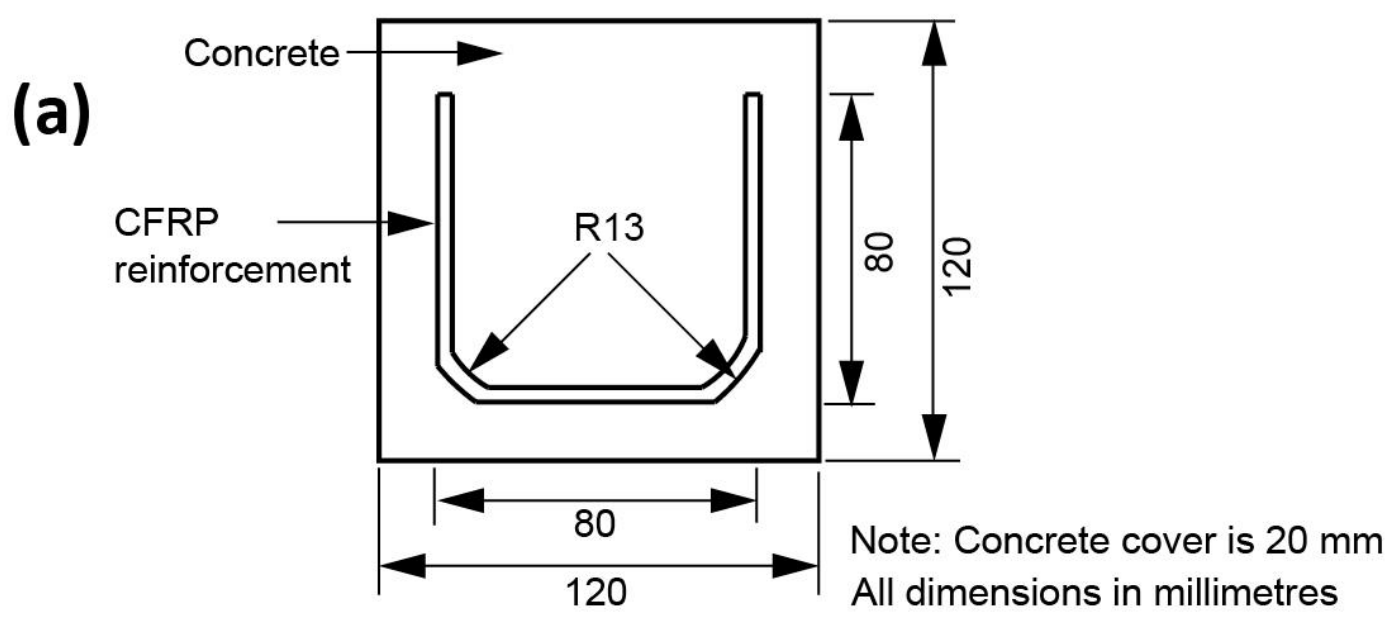

(b)

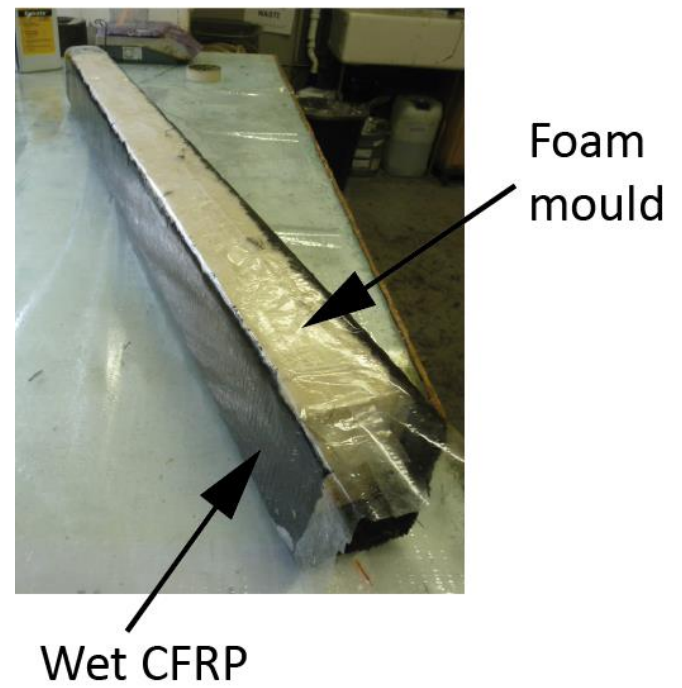

laminate

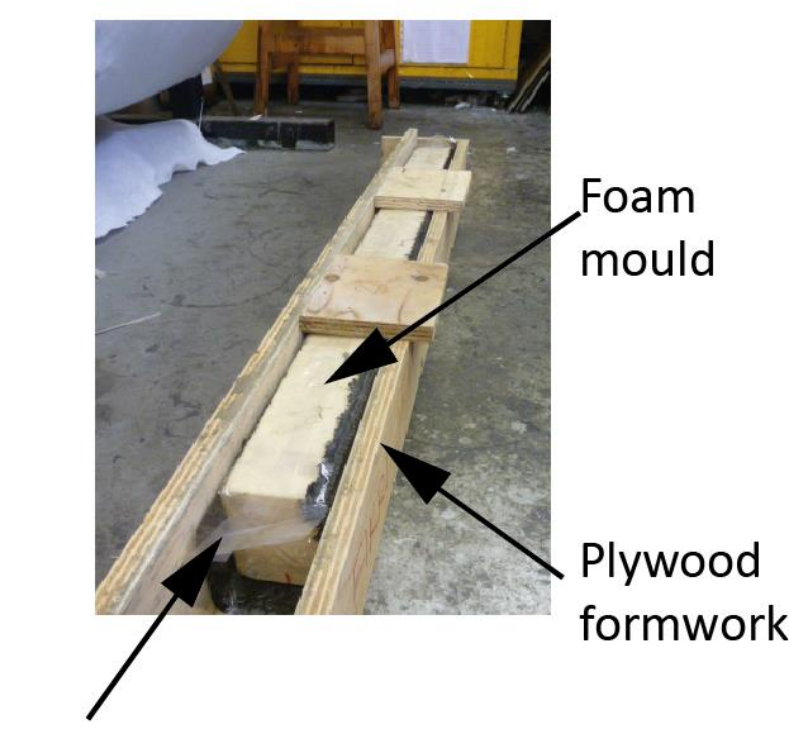

CFRP

laminate

Fig. 2. (a) Cross sectional dimensions of the plain U-channel (b) Wrapping the wet, rectangular CFRP laminate around a foam mould $\quad$ (c) Positioning of the CFRP wrapped foam mould within a plywood formwork 
(a)

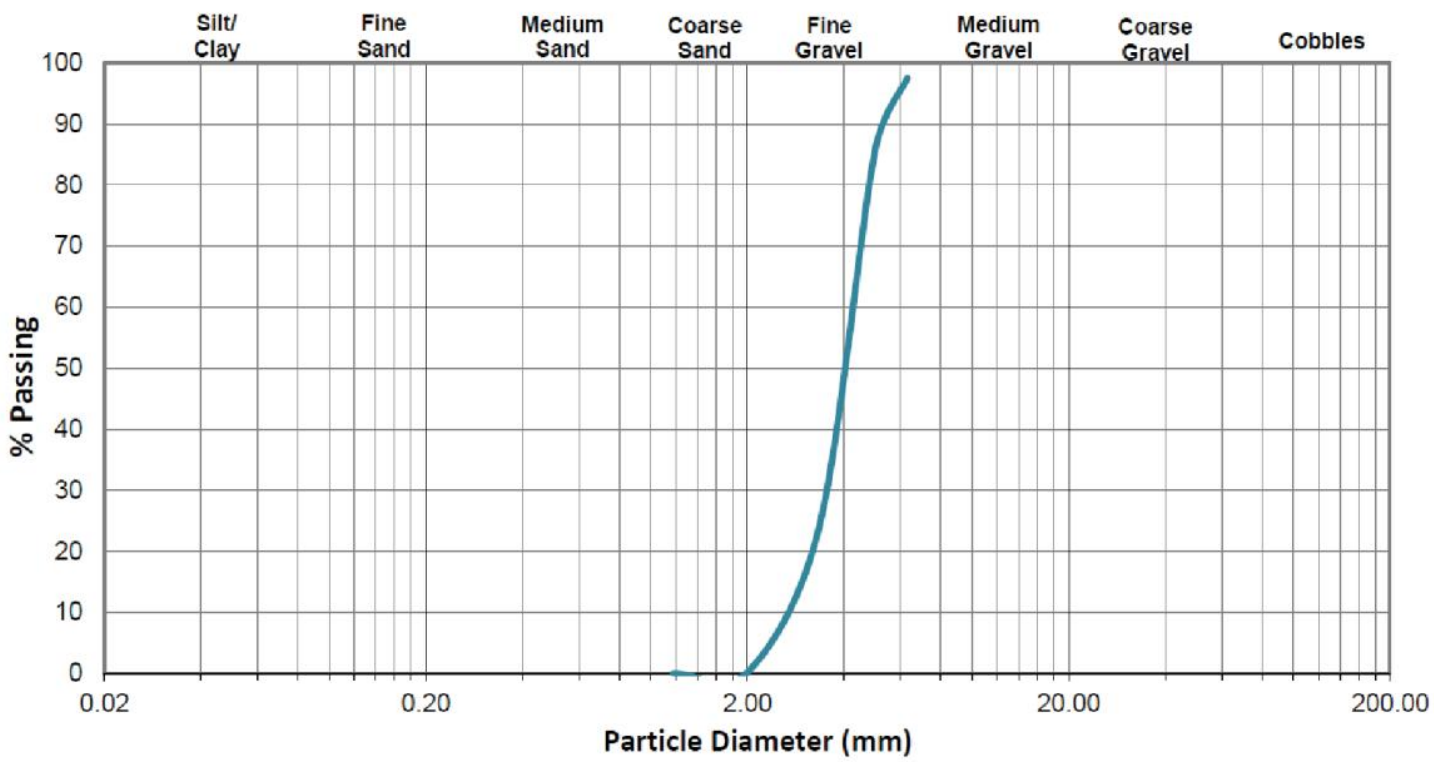

(b)

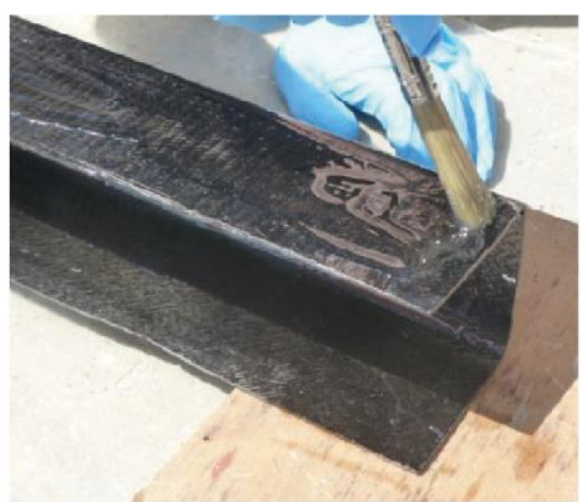

Application of epoxy resin on the surface of CFRP channel

Fig. 3. (a) Particle size distribution of aggregate coating all surfaces of the CFRP channel using epoxy resin

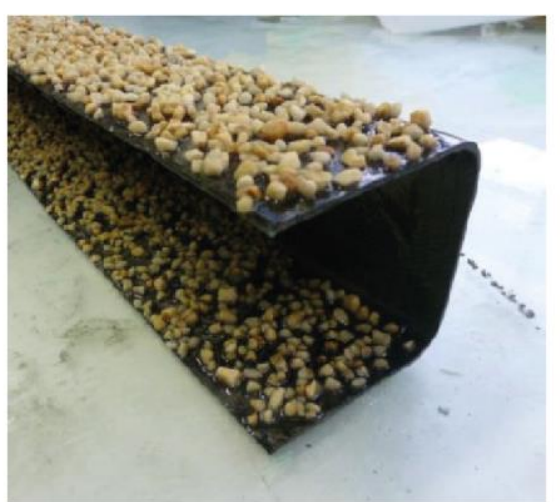

Aggregate coating was cured prior to the application of epoxy resin on other surfaces of CFRP channel

(b) An aggregate coating was applied on 
(a)
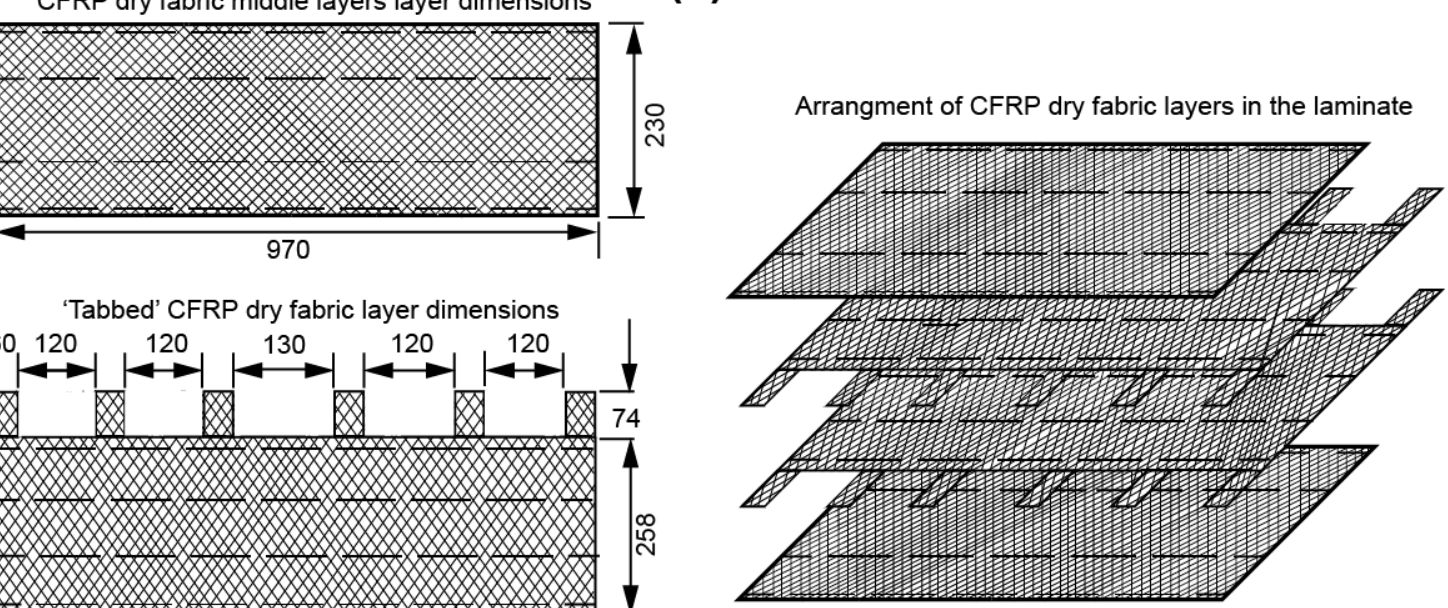

All dimensions in millimetres

(b)

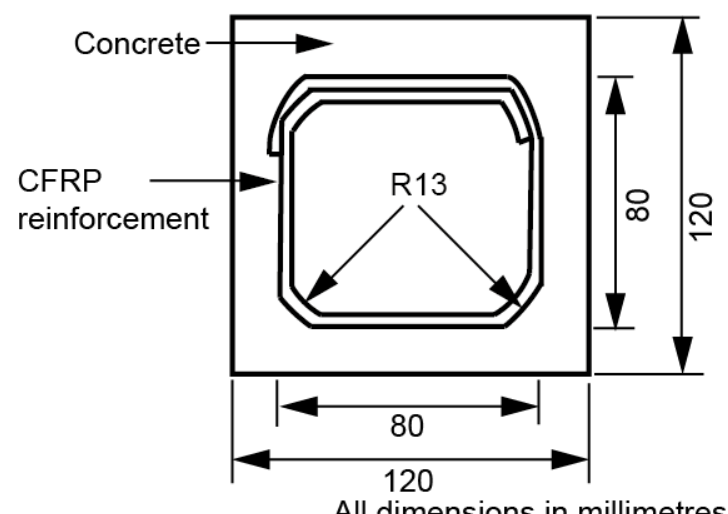

Note: Concrete cover is $20 \mathrm{~mm}$

Fig. 4. (a) Dimensions and arrangement of the CFRP dry fabric sheets for the lipped U-channel with intermittent closed loops

(b) Cross section dimensions of the lipped U-channel with intermittent closed loops 
(a)

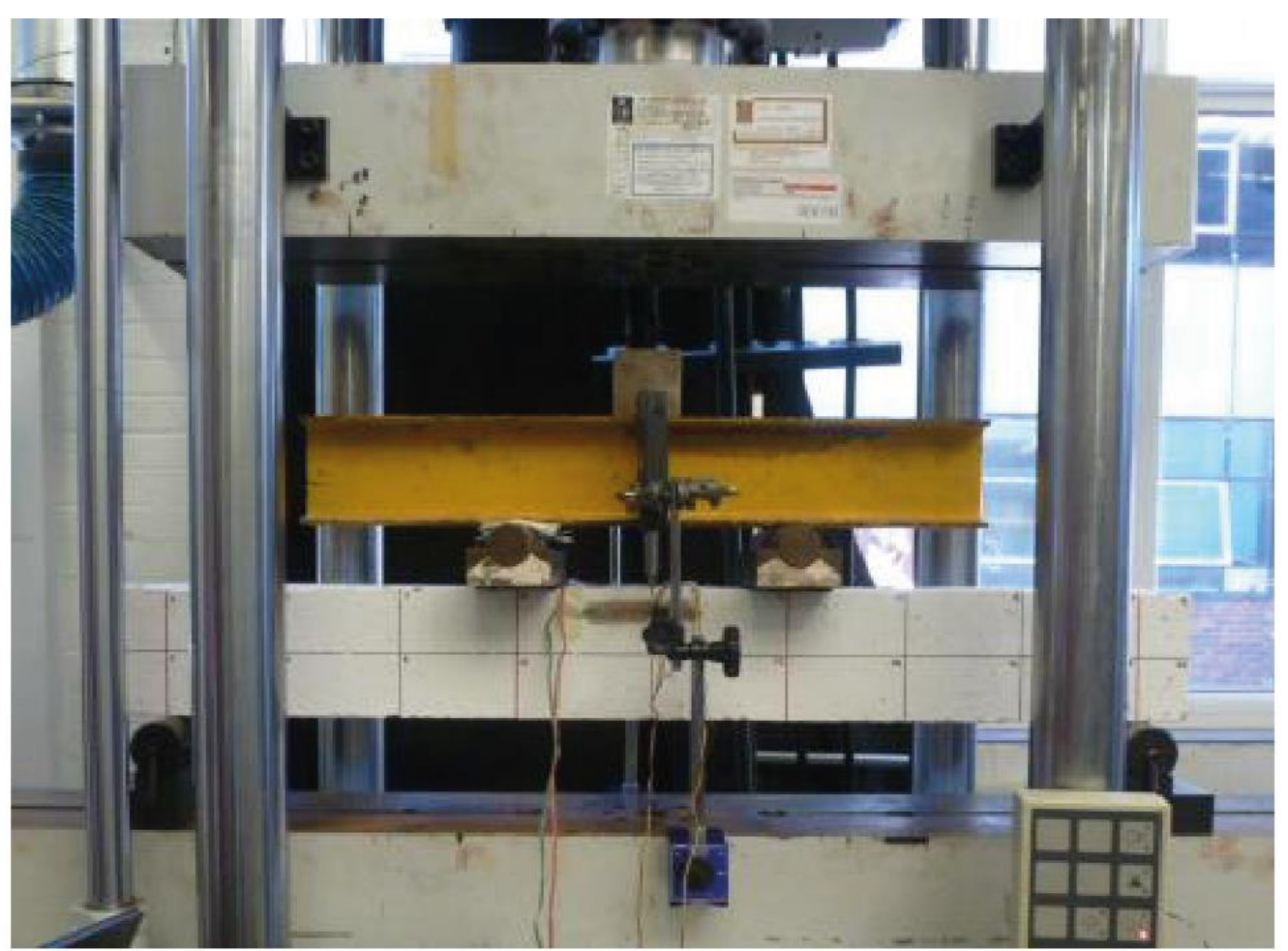

(b)

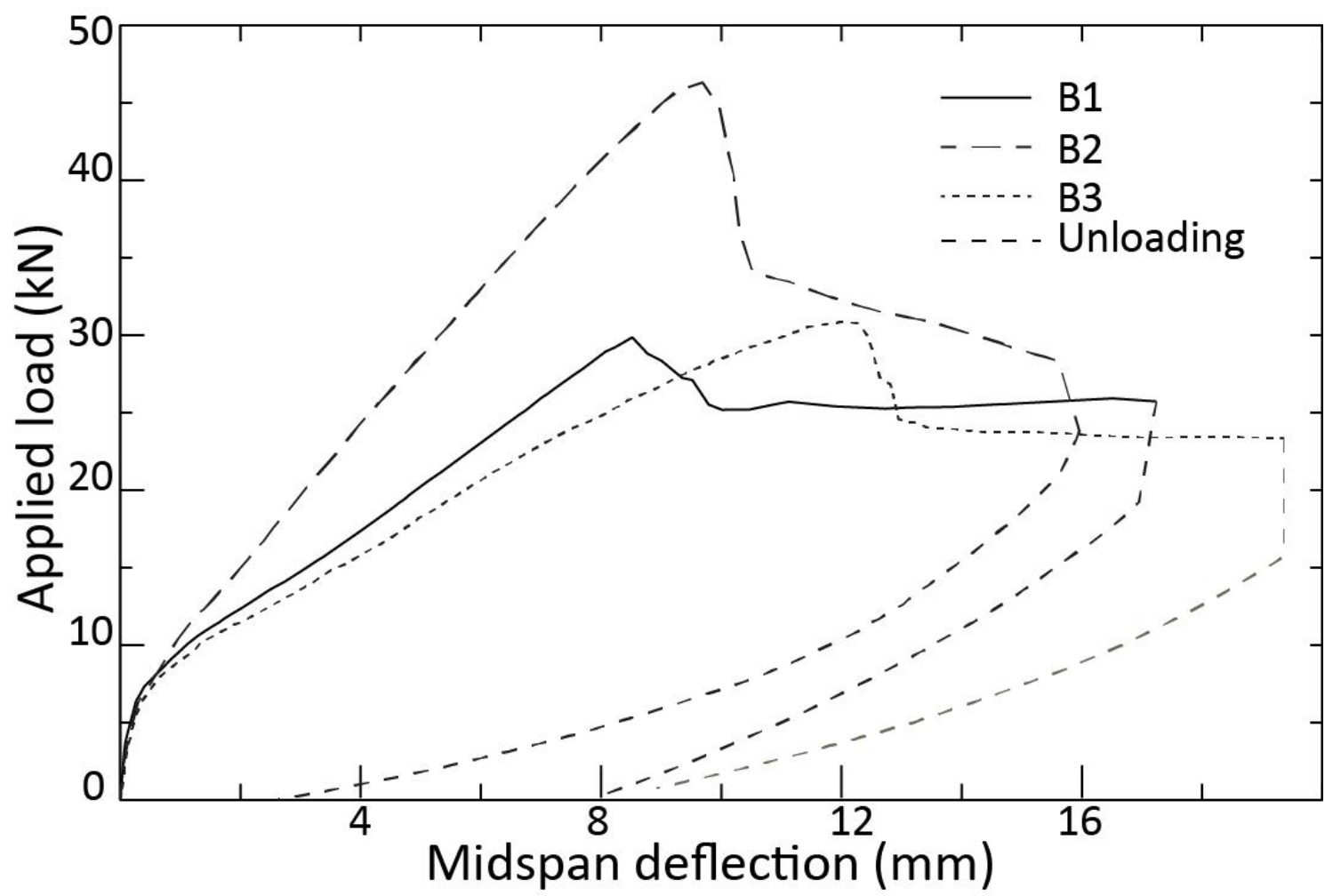

Fig. 5. (a) Four-point bending test arrangement (b) Applied load-midspan deflection relationships of the three beams 
(a)

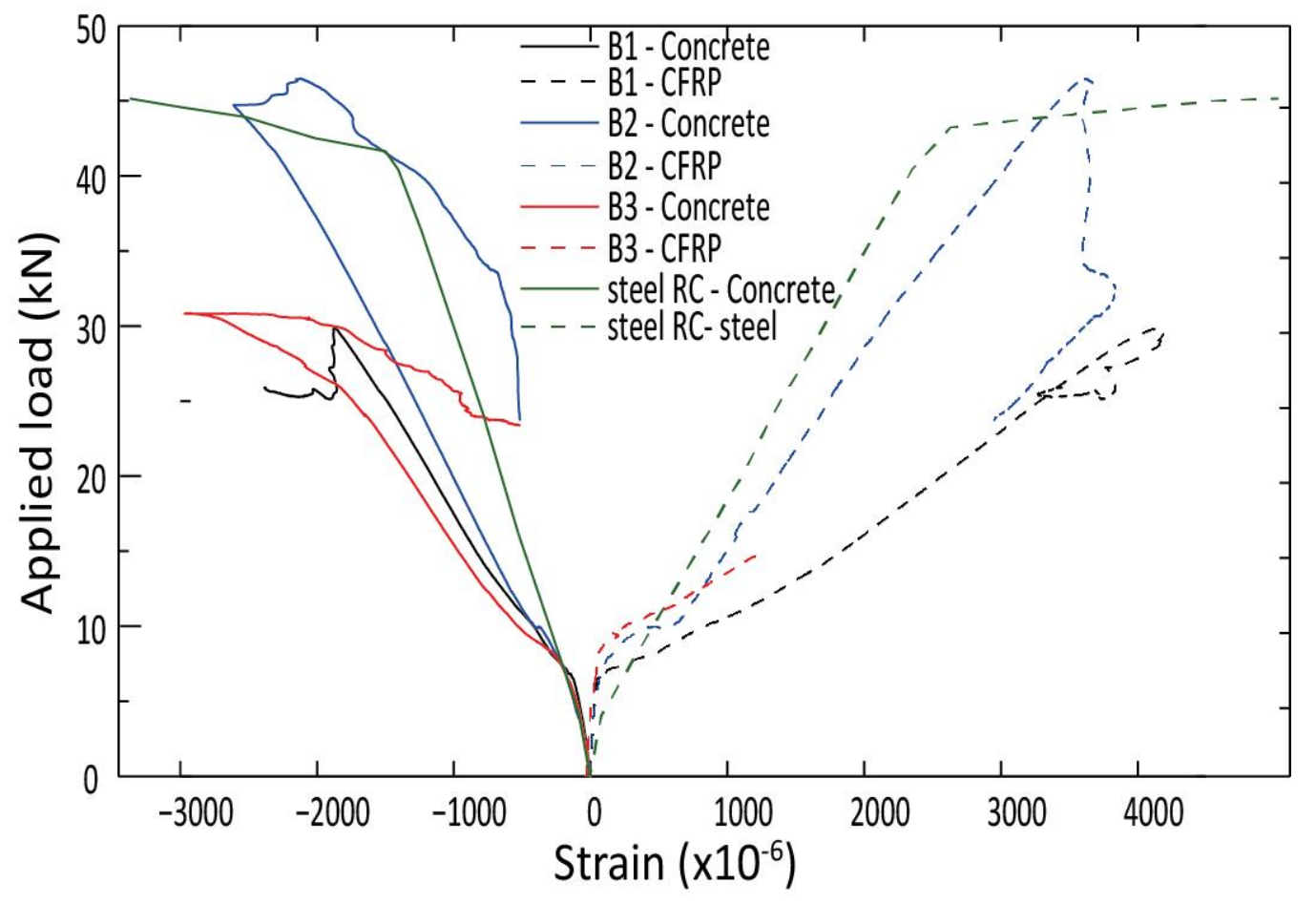

(b)

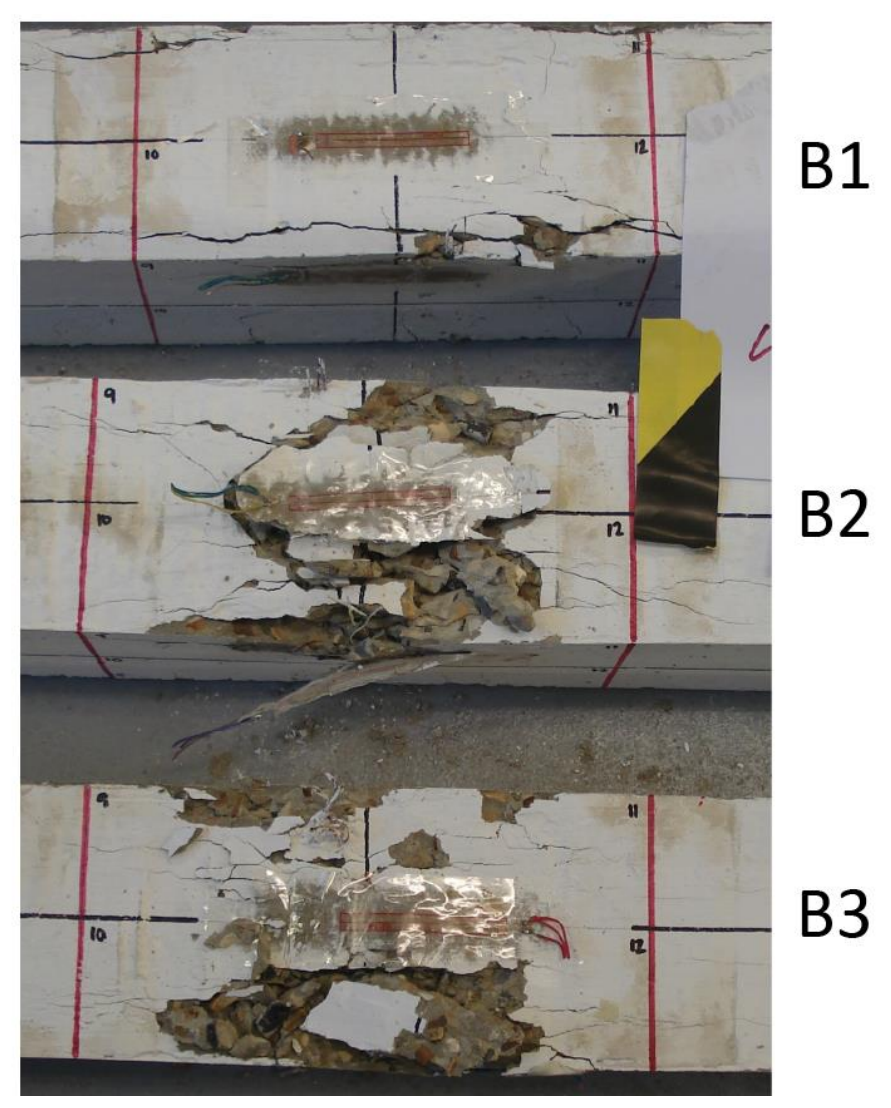

Fig. 6. (a) Applied load-strain relationships at midspan of the three beams (b) Failure mode of the three beams (top side view of the beams) 
B1
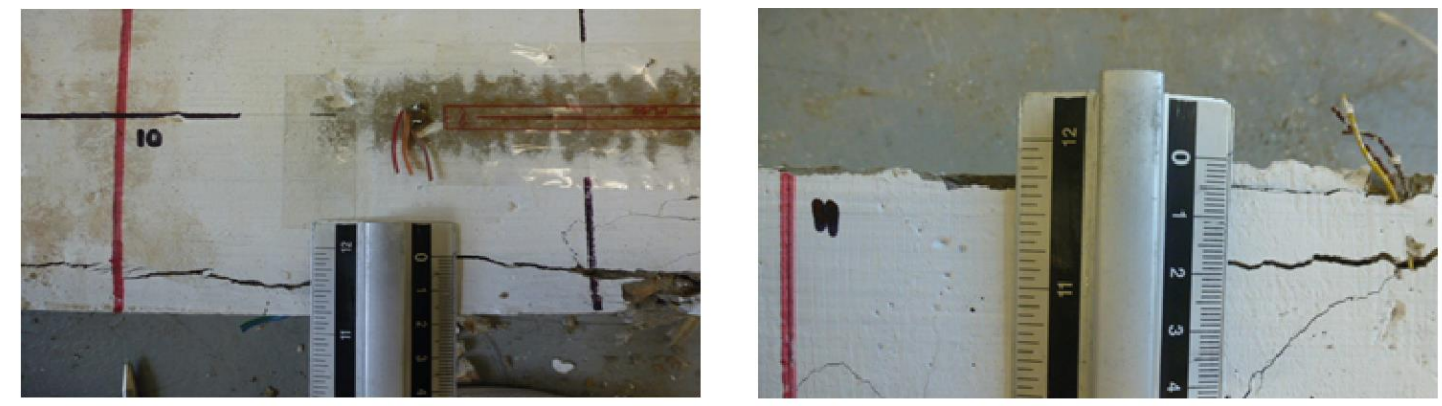

Distance to shear crack from beam edge $=\sim 20 \mathrm{~mm}$ Distance to horizontal crack on the side surface from beam top $=\sim 17 \mathrm{~mm}$

B2
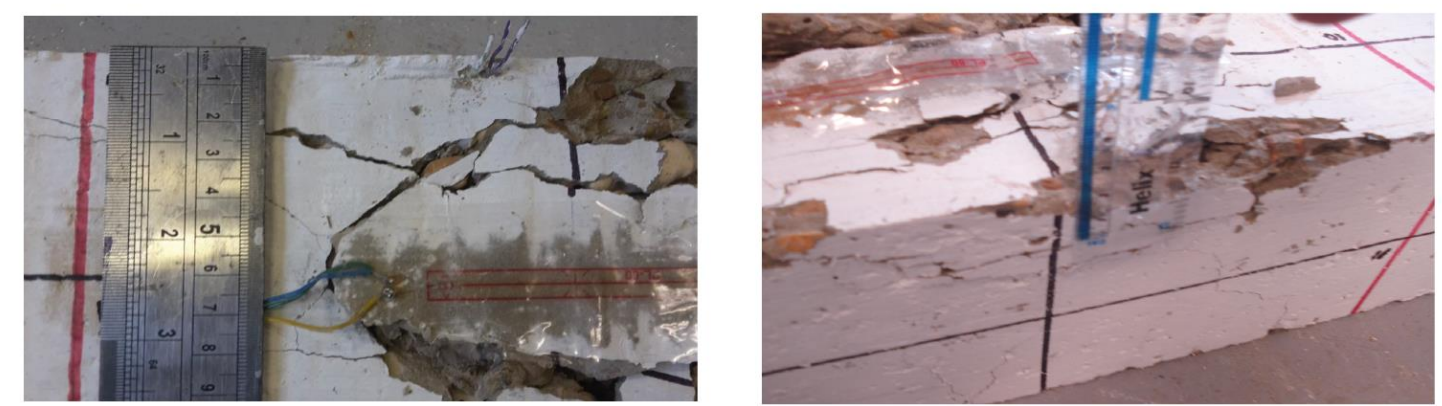

Distance to shear crack from beam edge $=\sim 20 \mathrm{~mm}$

Distance to horizontal crack on the side surface from beam top $=\sim 25 \mathrm{~mm}$

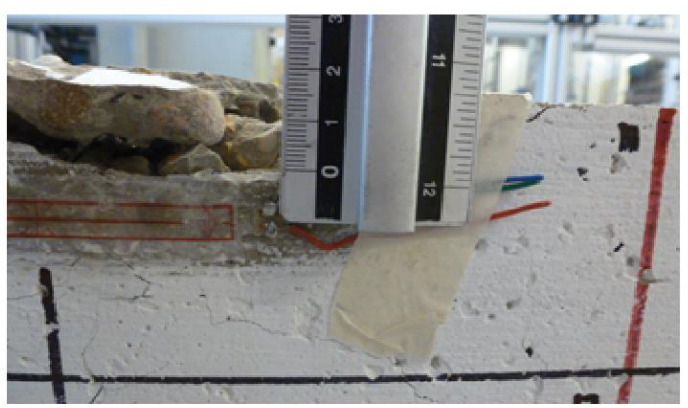

Distance to horizontal crack on the side surface from beam top $=\sim 15 \mathrm{~mm}$

Fig. 7. Horizontal 'splitting' crack locations on the top and side surfaces of all three beams 


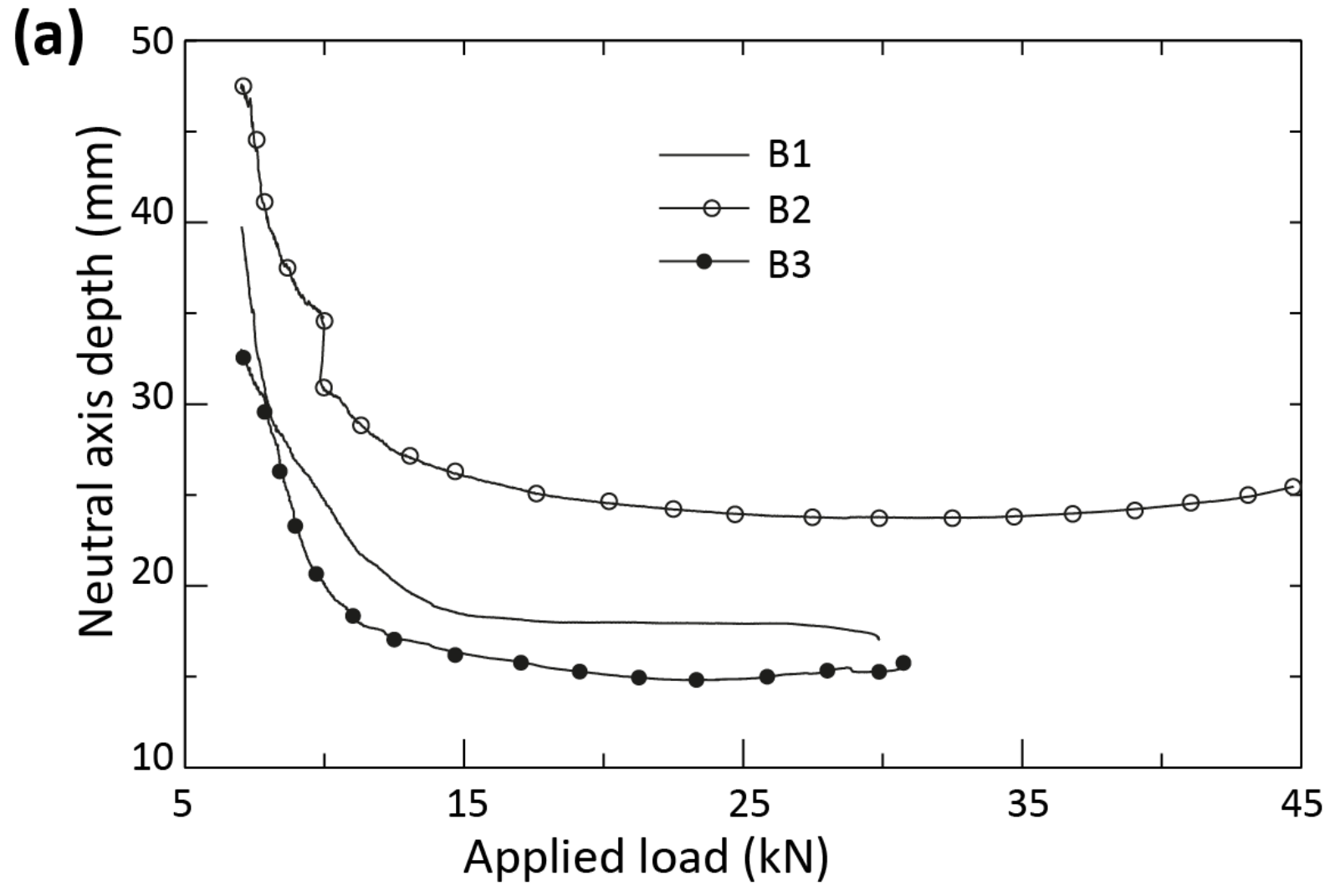

(b)

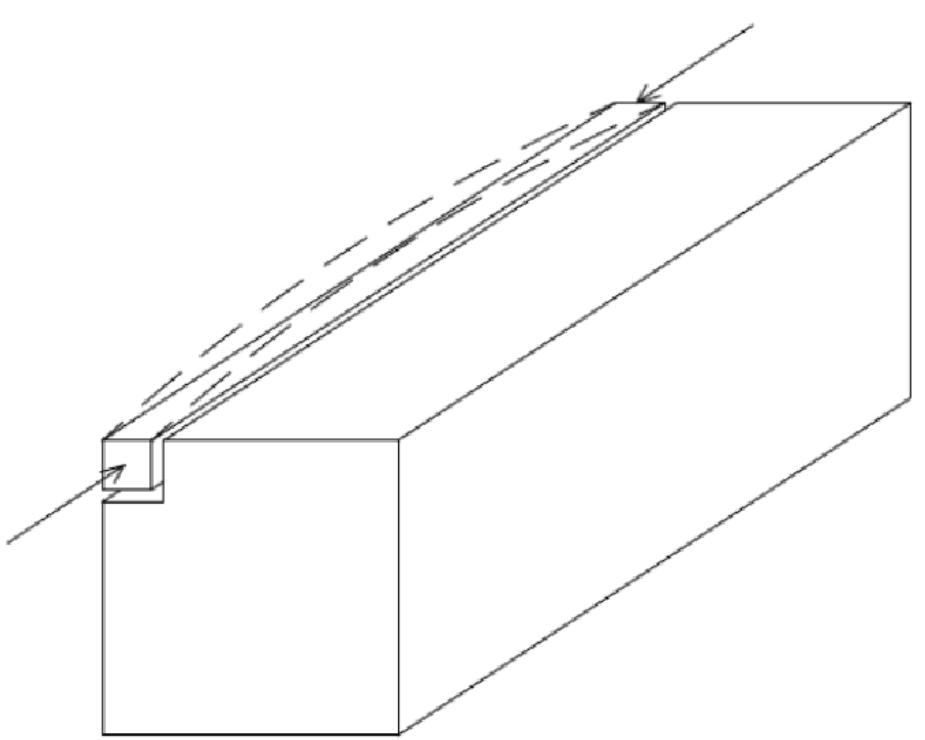

Fig. 8 (a) Applied load-neutral axis depth relationships of the three test beams (b) Laterally unsupported narrow slither of concrete became the equivalent of a slender concrete 'column' 
(a)

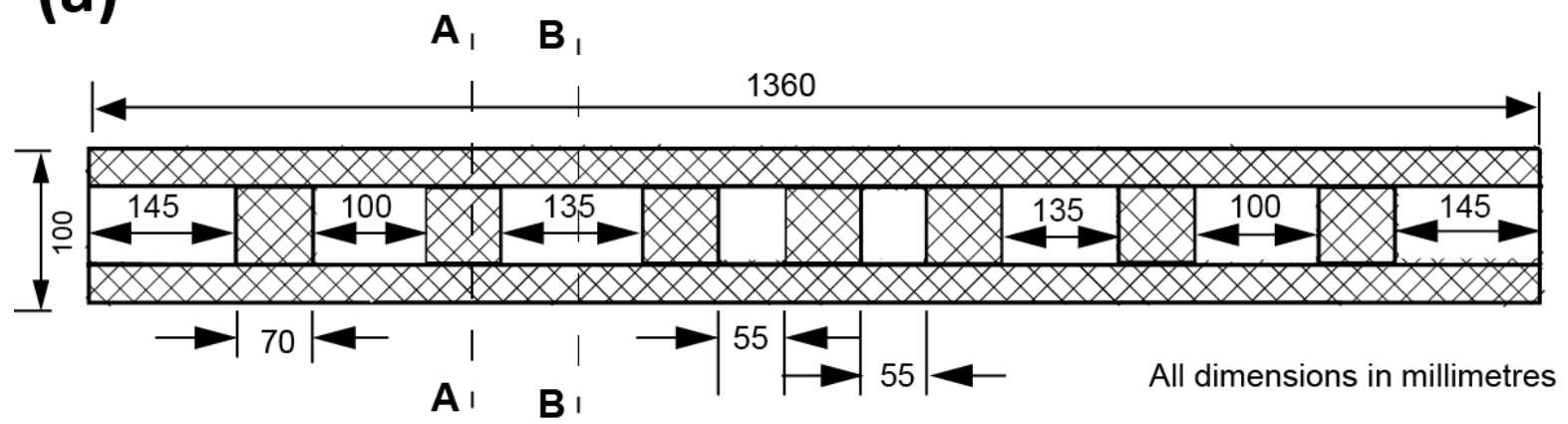

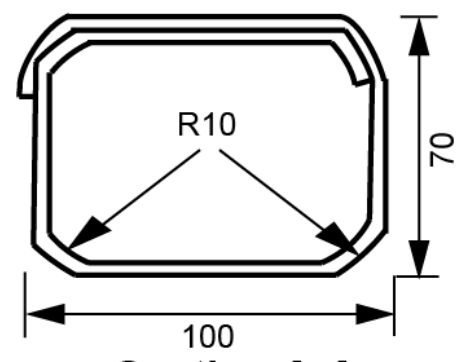

Section A-A

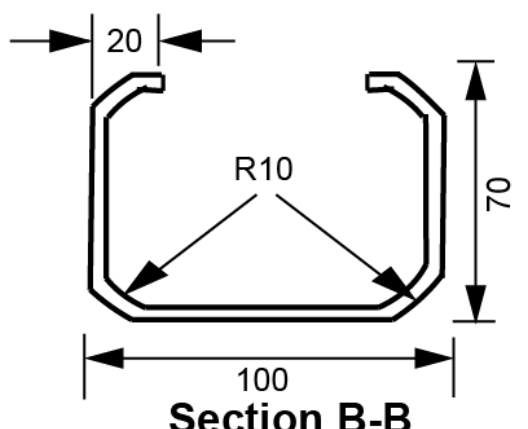

All dimensions in millimetres

(b)

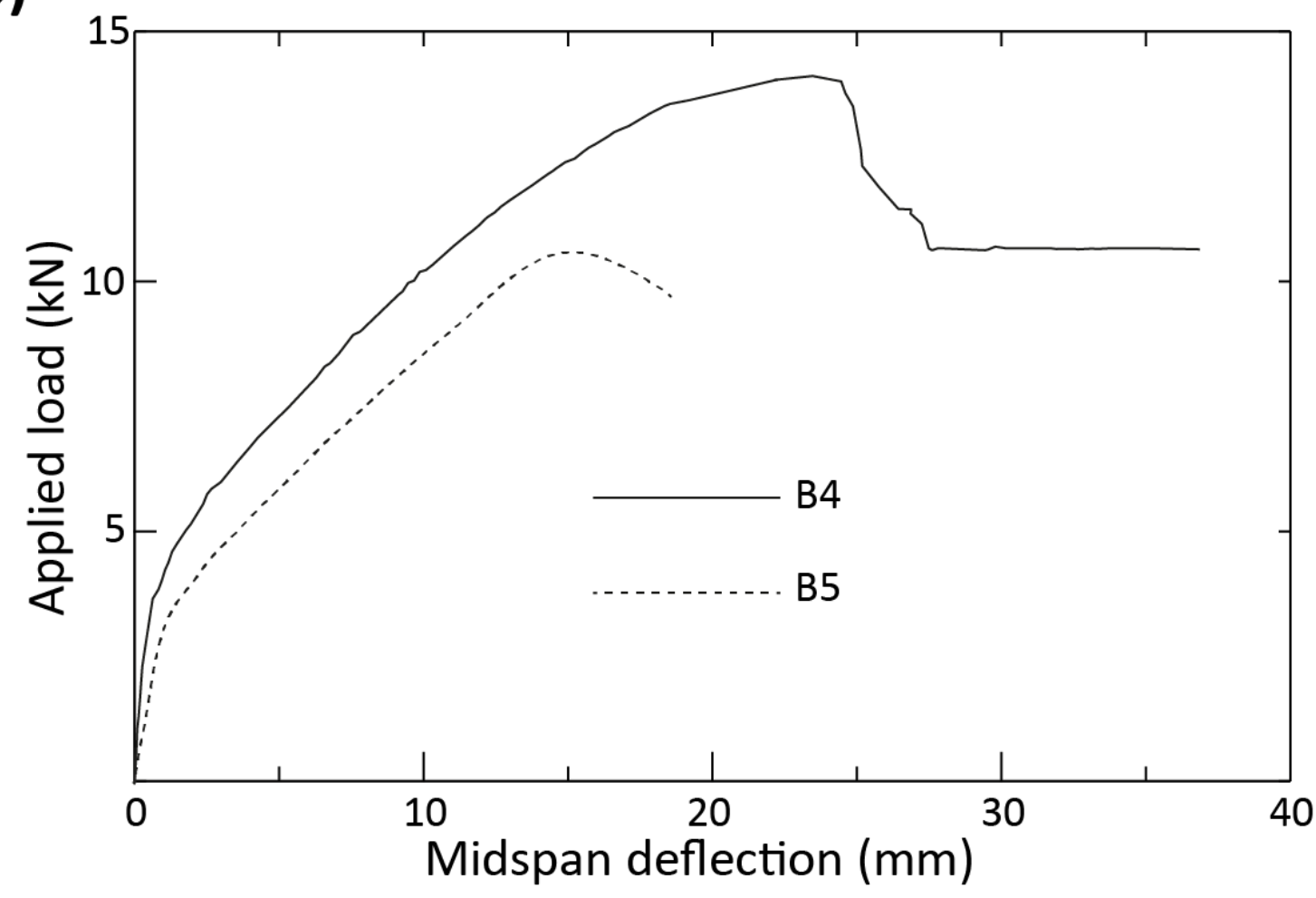

Fig. 9. (a) Dimensions of the CFRP reinforcement channel used in beam B4 $\quad$ (b) applied loadmidspan deflection relationships of the B4 and B5 


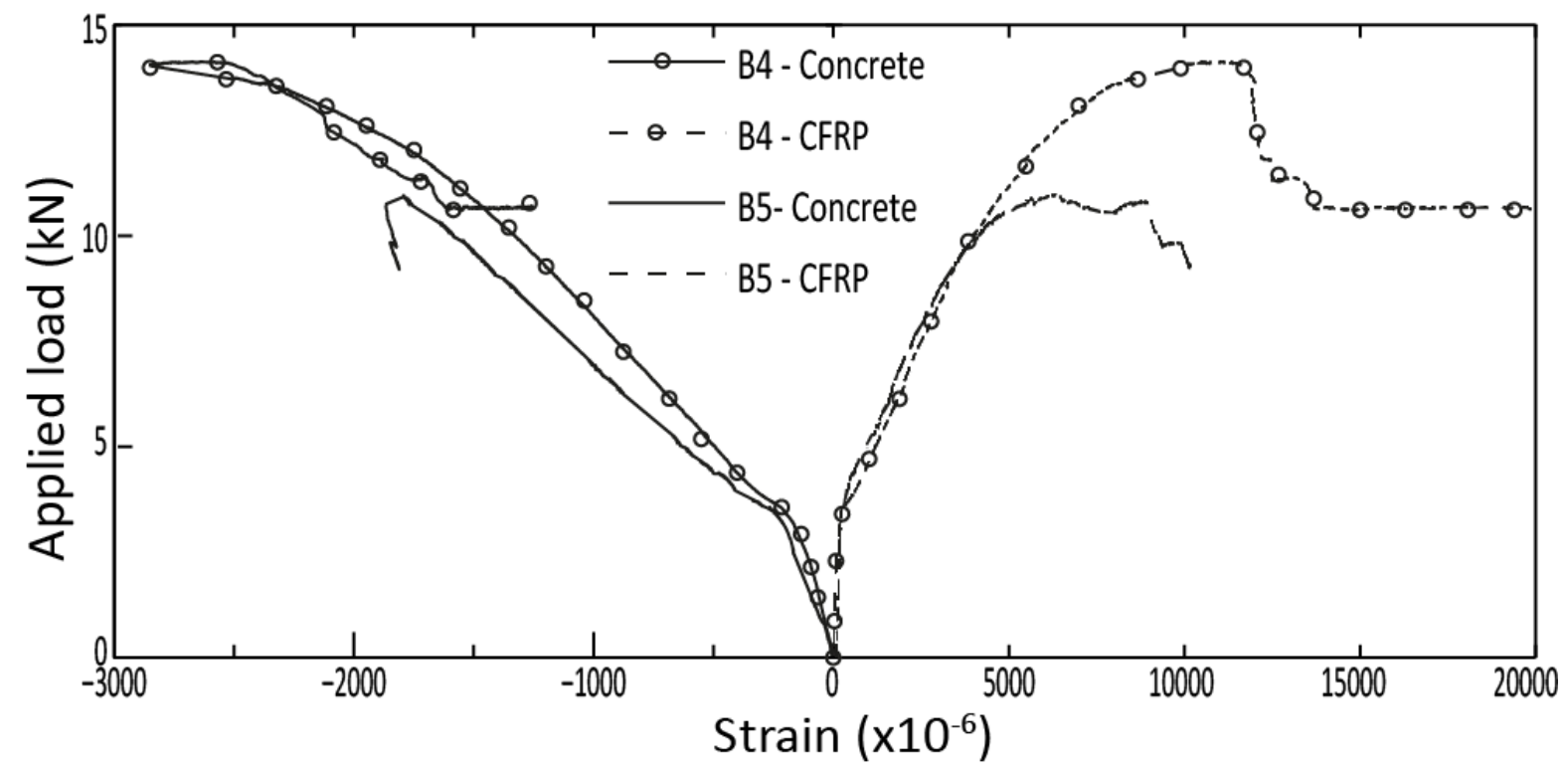

Fig. 10. Applied load-strains relationships at midspan of B4 and B5 